\title{
The compositional and configurational heterogeneity of matrix habitats shape woodland carabid communities in wooded- agricultural landscapes
}

Article

Accepted Version

Neumann, J. L., Griffiths, G. H., Hoodless, A. and Holloway, G. J. (2016) The compositional and configurational heterogeneity of matrix habitats shape woodland carabid communities in wooded-agricultural landscapes. Landscape Ecology, 31 (2). pp. 301-315. ISSN 0921-2973 doi:

https://doi.org/10.1007/s10980-015-0244-y Available at https://centaur.reading.ac.uk/46912/

It is advisable to refer to the publisher's version if you intend to cite from the work. See Guidance on citing.

To link to this article DOI: http://dx.doi.org/10.1007/s10980-015-0244-y

Publisher: Springer

All outputs in CentAUR are protected by Intellectual Property Rights law, including copyright law. Copyright and IPR is retained by the creators or other copyright holders. Terms and conditions for use of this material are defined in the End User Agreement. 


\section{www.reading.ac.uk/centaur}

\section{CentAUR}

Central Archive at the University of Reading

Reading's research outputs online 


\title{
The compositional and configurational heterogeneity of matrix habitats shape woodland carabid communities in wooded- agricultural landscapes.
}

\author{
Jessica L. Neumann ${ }^{1,3 *}$, Geoffrey H. Griffiths ${ }^{1}$, Andrew Hoodless ${ }^{2}$ and Graham J. Holloway ${ }^{3}$ \\ ${ }^{1}$ Department of Geography and Environmental Science, University of Reading, Reading, UK \\ ${ }^{2}$ Game and Wildlife Conservation Trust, Fordingbridge, Hampshire, UK \\ ${ }^{3}$ Centre for Wildlife Assessment and Conservation, Department of Biological Sciences, University \\ of Reading, Reading, UK
}

\begin{abstract}
Context

Landscape heterogeneity (the composition and configuration of matrix habitats) plays a major role in shaping species communities in wooded-agricultural landscapes. However, few studies consider the influence of different types of semi-natural and linear habitats in the matrix, despite their known ecological value for biodiversity.
\end{abstract}

\section{Objectives}

To investigate the importance of the composition and configuration of matrix habitats for woodland carabid communities and identify whether specific landscape features can help to maintain long-term populations in wooded-agricultural environments.

\section{Methods}

Carabids were sampled from woodlands in 36 tetrads of $4 \mathrm{~km} 2$ across southern Britain. Landscape heterogeneity including an innovative representation of linear habitats was quantified for each tetrad. Carabid community response was analysed using ordination methods combined with variation partitioning and additional response trait analyses.

\section{Results}

Woodland carabid community response was trait-specific and better explained by simultaneously considering the composition and configuration of matrix habitats. Semi-natural 
and linear features provided significant refuge habitat and functional connectivity. Mature hedgerows were essential for slow-dispersing carabids in fragmented landscapes. Species commonly associated with heathland were correlated with inland water and woodland patches despite widespread heathland conversion to agricultural land, suggesting that species may persist for some decades when elements representative of the original habitat are retained following landscape modification.

\section{Conclusions}

Semi-natural and linear habitats have high biodiversity value. Landowners should identify features that can provide additional resources or functional connectivity for species relative to other habitat types in the landscape matrix. Agri-environment options should consider landscape heterogeneity to identify the most efficacious changes for biodiversity.

\section{Keywords}

Agriculture; carabid communities; landscape heterogeneity; life-history traits; linear features; matrix habitats; semi-natural habitat; variation partitioning; woodland

\section{Introduction}

Changes to European woodland-agricultural environments have occurred over thousands of years; however the post-Second World War period saw an unprecedented rate of landscape modification (Aviron et al., 2005; Hendrickx et al., 2007). Landscape features such as woodlands, hedgerows and natural grasslands were destroyed to develop larger, intensively managed agricultural fields, or converted to non-native commercial coniferous woodland (Firbank et al., 2007; Mason, 2007). These changes have driven significant biodiversity declines in agricultural and semi-natural habitats (Aviron et al., 2005; Devictor and Jiguet, 2007; Radford and Bennett, 2007; Piqueray et al., 2011). Land-use demands are projected to increase (Lawton et al., 2010) and guidance on how to sustain biodiversity with minimal impact on economic productivity is urgently needed (Haslem and Bennett, 2008; Fahrig et al., 2011; Duflot et al., 2014). With increasing awareness of the value of integrated landscape scale action which can meet the needs of biodiversity and people, understanding how landscape factors influence species communities has consequently become a key topic in conservation biology.

A fundamental concept in macroecology is that landscape heterogeneity influences species richness, abundance and the overall composition of species communities in a landscape (Purtauf et al., 2005; Mayfield et al., 2010; Duflot et al., 2014). Landscape heterogeneity is defined by two 
components; landscape composition (the number and proportions of different landcover types) and landscape configuration (the spatial arrangement of different landcover types) (Barbaro et al., 2007; Fahrig et al., 2011). Variations in both these components influence ecological processes such as environmental filtering and competitive exclusion and facilitation which play key roles in determining the composition and community structure of species assemblages in a landscape (Schweiger et al., 2005; Mayfield et al., 2010).

Scientists have adopted complementary approaches for determining the importance of landscape heterogeneity for biodiversity. Particular attention has been directed towards the spatial landscape patterning of focal habitat types; considering the extent and configuration of a focal habitat, and quantifying the effects of habitat loss, isolation and fragmentation on taxa of interest (e.g. Fahrig, 2003; Cushman and McGarigal, 2003; Öckinger and Smith, 2006). Other studies have considered the biodiversity benefits provided by 'countryside elements' such as gardens, hedgerows and field margins, but often these have been focussed at the local scale without incorporating all the interactions from the wider landscape (Green et al., 1994; Daily et al., 2001; Mayfield and Daily, 2005; Gardiner, 2007). Recently, it has been recognised that methods encompassing both the spatial landscape pattern and the composition of the surrounding matrix provide a more detailed understanding of how species respond in woodedagricultural mosaics (e.g. Heikkinen et al., 2004; Barbaro et al., 2007; Hendrickx et al., 2007; Fahrig et al., 2011). This shift away from the traditional habitat-matrix paradigm (Fahrig et al., 2011), recognises that the matrix plays an important role in shaping community assemblages by influencing species responses such as dispersal, movement, breeding and feeding behaviour and predation risks (Schweiger et al., 2005; Haslem and Bennett, 2008). Adopting a 'whole landscape mosaic' approach therefore helps ascertain the value of different landscape features for biodiversity, while also considering how the different components interact to affect species distributions and community structure (Bennett et al., 2006; Haslem and Bennett, 2008).

Consistently, semi-natural habitats and 'green-veining' (Schweiger et al., 2005) have been found to be of significant importance for a variety of taxa (Vanbergen et al., 2005; Hendrickx et al., 2007; Billeter et al., 2008). Despite often contributing to a relatively small proportion of the total landcover, semi-natural and linear features can provide functional connectivity, i.e., perceived connectedness by organisms which have different ecological requirements (McGarigal and Ene, 2012), and alternative useable habitat for species in modified landscapes (Hinsley and Bellamy, 2000; Devictor and Jiguet, 2007; Gardiner, 2007). Many semi-natural habitats and linear features are also directly amenable to landscape management modification and thus are of practical 
conservation interest (Haslem and Bennett, 2008; Oliver et al., 2010). The ecological functions provided by such features are known to vary greatly depending on their composition, e.g., an orchard compared with a mature hedgerow or larger expanse of scrubland; but also their spatial configuration within the matrix, e.g., hedgerows adjacent to different types of landcover provide varying benefits for different species groups (see Hinsley and Bellamy, 2000; Larcher and Baudry, 2013). There are a few studies that have successfully identified the individual contributions of different semi-natural habitats for their taxa of interest, thus providing a better insight for targeting conservation efforts (see Barbaro et al., 2007; Devictor and Jiguet, 2007; Haslem and Bennett, 2008). However, the value of different linear features and the interactive role they play within the matrix has not been explored within a whole landscape mosaic context. This is likely to be because accurate spatial data detailing linear features are not readily available and are timeconsuming to create. The importance of features such as hedgerows, ditches, field margins and conservation headlands is formally recognised in European policy through agri-environment schemes (Billeter et al., 2008; Davey et al., 2010); yet landscape scale interpretation largely relies on evidence extrapolated from local scale studies (e.g. Green et al., 1994; Hinsley and Bellamy, 2000; Gardiner, 2007). In a few cases where linear habitats have been incorporated at the wider landscape scale, consideration of their interactions within the matrix and importance for biodiversity has been limited. This is because the different types of linear feature have been aggregated and analysed together as one variable, and often in combination with other types of semi-natural habitat (e.g. Schweiger et al., 2005; Hendrickx et al., 2007; Billeter et al., 2008; Duflot et al., 2014).

This paper addresses these knowledge gaps and explores how the composition and configuration of whole landscape mosaics, including a detailed representation of semi-natural and linear features, affects woodland invertebrate communities (Coleoptera; Carabidae) in $362 \times 2 \mathrm{~km}$ study tetrads across southern Britain (Figure 1). Carabids have been extensively studied within woodland and agricultural ecosystems and are considered to be highly sensitive to landscape modification making them useful bio-indicators of landscape change (Taboada et al., 2004; Vanbergen et al., 2005; Barbaro et al., 2007; Kang et al., 2012). It is generally accepted that carabid life-history traits that have resulted from evolutionary adaptation to environmental conditions over time will govern how individuals respond to landscape heterogeneity; specifically traits related to carabid movement, dispersal, phenology and habitat specialism functions (Lavorel et al., 1997; Ribera et al., 2001; Lindborg and Eriksson, 2004; Schweiger et al., 2005; Gibb et al., 2006; Barbaro and van Halder, 2009; Oliver et al., 2010; Piqueray et al., 2011; Duflot et al., 2014). Adopting a trait approach provides greater insight into the mechanisms that 
determine how landscape factors govern community composition and ultimately, a more accurate indication of long-term population stability in the face of ongoing landscape change (Brouwers and Newton, 2009a; Oliver et al., 2010).

This study addresses four key questions: i) how do woodland carabid communities respond to the composition (the number and proportions of different landcover types) and configuration (the spatial arrangement of different landcover types) of whole landscape mosaics in woodedagricultural environments? Specifically, ii) do semi-natural habitats and linear features retain their importance for biodiversity as has been indicated in previous studies, when they are considered as individual components and not grouped and analysed together (e.g. Schweiger et al., 2005; Vanbergen et al., 2005; Hendrickx et al., 2007; Billeter et al., 2008)? iii) What is the relative importance of landscape composition and landscape configuration for shaping woodland carabid communities, and can greater understanding be achieved by considering both these components of landscape heterogeneity together? Finally iv) can carabid community response to landscape heterogeneity be determined by five carabid life-history and ecological traits? It is hypothesized that smaller-bodied species will respond to different landscape features in comparison with larger carabids. There is generally a positive correlation between body-size and movement rate/dispersal power, however it also expected that interactions with other traits such as flight capability and habitat specialization will be of importance (Kotze and O'Hara, 2003; Schweiger et al., 2005; Barbaro and van Halder, 2009). Specifically, it is proposed that larger, flightless species typical of woodland habitats will be negatively affected by the presence of transport routes (main roads and railways) that pose a barrier to movement (Koivula, 2005), but positively associated with woodland patches and mature hedgerows which, as ecologically stable environments, facilitate movement (Aviron et al., 2005; Jopp and Reuter, 2005). Conversely, smaller species and generalists within the woodland community will be associated with ephemeral habitats including road verges and woodland edges.

\section{Methods}

\section{Study region}

The study was undertaken in central southern England (Figure 1), a region of intensive arable and improved grassland land-use, interspersed with woodland patches varying in size, shape, and isolation. The climate is temperate, with a mean annual temperature of $10.2^{\circ} \mathrm{C}$ and precipitation averaging $850 \mathrm{~mm}$. Topography is low lying with an average elevation of $140 \mathrm{~m}$ above sea level. The principal soils are clay enriched brown earths and calcareous lithomorphic substrate. 


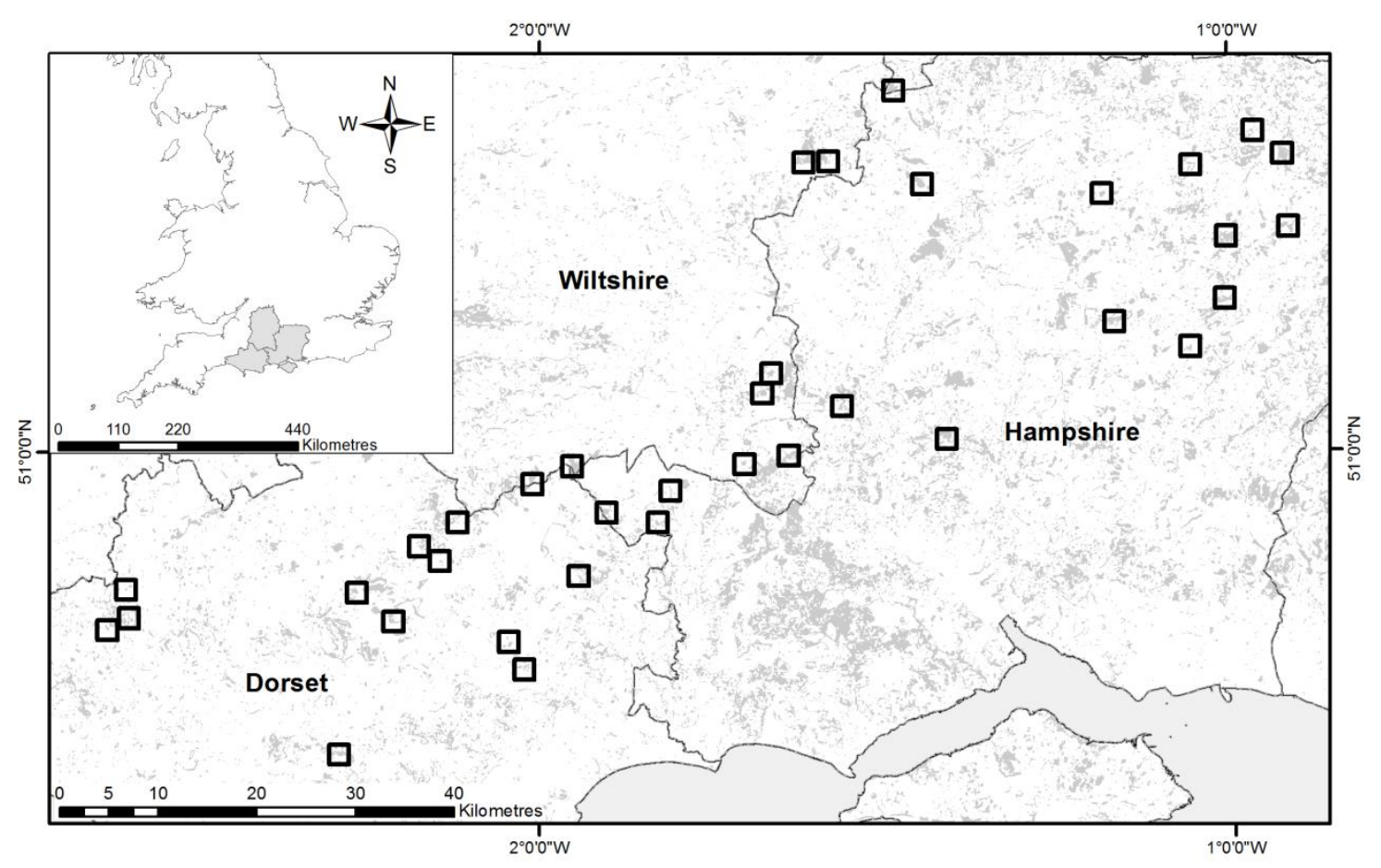

Figure 1: Location of the study region and $362 \times 2 \mathrm{~km}$ study tetrads in central southern Britain. Grey shading indicates native broadleaved and mixed woodland cover derived from CEH Landcover 2000 (Fuller et al., 2002).

\section{Study design}

Thirty-six sample woodlands representing a range of sizes, shapes and densities (configuration) in the landscape were identified. All were classified as broadleaved although some larger woods also contained areas of conifers mixed with deciduous trees (Forestry Commission, 2011). Each sample woodland was located at the centre of a $2 \times 2 \mathrm{~km}$ study tetrad from which landscape variables were measured (Table 1). $2 \times 2 \mathrm{~km}$ was deemed large enough to incorporate variation in landscape heterogeneity, while also small enough to allow replication across the study region and be relatable to farm scale management options (Haslem and Bennett, 2008). Tetrads avoided large urban areas, floodplains, lowland heath and coastal regions. It was also ensured that variations in slope, elevation and aspect (derived from a Digital Terrain Model (Ordnance Survey, 2012)) were statistically comparable between all study tetrads. Finally, tetrads did not overlap to ensure there was no duplication in the landscapes sampled (Radford and Bennett, 2007).

\section{Carabid sampling}

Carabid beetles were collected from the interior and edge habitat of each sample woodland using pitfall traps (diameter $60 \mathrm{~mm}$, depth $80 \mathrm{~mm}$ ). Two traps were set at the woodland centre, 
with further pairs also placed at the most Northerly, Southerly, Easterly and Westerly-facing woodland edge adjacent to non-woodland habitat, providing 10 traps in total per tetrad. This provided a systematic sampling method and ensured interior woodland specialists and edgesensitive species with different life-history traits were recorded. The decision to use 10 traps was based on similar studies conducting carabid sampling at landscape scales (Aviron et al., 2005; Purtauf et al., 2005). In each tetrad, traps were set for a 14 day period between early May and mid-August which coincides with the greatest level of carabid activity (Aviron et al., 2005; Luff, 2007). The sampling fortnight for each tetrad was randomly assigned during the May-August period to avoid clusters of sites in close spatial proximity trapping species during the same time period. All pitfall traps were one third filled with ethylene glycol $(50 \%)$ and water (50\%) and individual pitfalls within each pair were separated by a $15 \mathrm{~m}$ gap. This is considered to be above the distance of interaction between pitfall traps when sampling carabid beetles (Digweed et al., 1995; Ward et al., 2001). All individuals collected were pooled for each tetrad and identified to species level using Luff (2007) and a binocular microscope.

\section{Life-history and ecological traits}

Five carabid life-history and ecological traits (body size, wing system, breeding season, dominant habitat preference and soil moisture requirements) that related to dispersal, phenology and habitat specialism functions were selected (Schweiger et al., 2005; Barbaro and van Halder, 2009; Duflot et al., 2014) (refer to Table S1 in Appendix 1). Values recorded for each trait were obtained from British carabid field guides (Forsythe, 2000; Luff, 2007) and with reference to other published literature (Ribera et al., 2001; Taboada et al., 2004; Schweiger et al., 2005; Barbaro and van Halder, 2009). Average body-size ( $\mathrm{mm}$ ) was recorded as a continuous value (range $3.1 \mathrm{~mm}$ to $25 \mathrm{~mm}$ ) for each species measuring from the tip of the mandibles to the apex of the elytra. In the Results and Discussion sections, the term 'small-bodied' refers to carabid species measuring less than $4.5 \mathrm{~mm}$ in length and 'large-bodied' applies to those that are greater than $10 \mathrm{~mm}$. Carabid wing system was classified into 3 categories (macropterous, dimorphic and apterous); breeding season into 3 categories (spring, summer and autumn); habitat preference into 6 categories (woodland, grassland, agricultural, heath, open and all habitats) and soil moisture requirements into 4 categories (near running or standing water, damp soil, damp-dry soil and dry soil). Habitat preference and soil moisture requirement categories were chosen to reflect the natural variability of traits possessed by carabids, while ensuring that each category was large enough (at least 100 individuals from 6 species) to avoid statistical bias (Duflot et al., 2014). 


\section{Landscape heterogeneity spatial analysis}

ArcGIS v.10.0 (ESRI, 2011) was used to digitize and quantify the whole landscape matrix in each 2 $x 2 \mathrm{~km}$ tetrad. Three groups of explanatory variables were recorded: (i) 12 landscape composition variables (number and proportional cover of different landcover types), (ii) 12 landscape configuration variables (metrics representing shape and spatial patterning of landcover variables) and (iii) 2 additional constraining variables (Table 1).

\section{Landscape composition variables}

The dominant landcover types within the study region were included plus other habitats considered potentially significant for woodland carabids, either in terms of their anthropogenic effects (urban areas, main roads and railways), or direct relevance as semi-natural or linear habitat in farmed landscapes (Table 1). Where feasible, some habitat types were combined to ensure the heterogeneity of the whole landscape mosaic was represented using the most parsimonious number of variables: broadleaved and mixed woodland possess similar ecological characteristics and are often spatially contiguous within woodland patches, while scrub and rough grassland were interchangeably classified by OS MasterMap data (Ordnance Survey, 2010) (Table 1). Scattered trees included all forms of open canopy tree cover (broadleaved and coniferous species, orchards and parkland trees). Inland water encompassed all forms of running and standing freshwater including small rivers, streams, lakes, ponds, marshes and reed beds. Main transport routes that intersected the landscape matrix included motorways, A roads, B roads and railways. Minor residential roads were not included as these were spatially correlated with the urban land-use polygons. Unpaved tracks and lanes including woodland rides were also excluded as they were unlikely to pose the same effects as tarmacked main roads. All hedgerows were classified into three categories $(\mathrm{H} 1-\mathrm{H} 3)$ based on their structural characteristics and digitised as polylines from the latest Google Maps aerial imagery and field observations:

- $\quad H 1$ : Hedgerows which are low and intensively managed; without trees. Up to approximately 1.5 metres high; average width 2.5 metres

- $\quad$ H2: Hedgerows which contain small / juvenile trees or taller shrubs. Greater than 1.5 metres high; average width 7 metres

- H3: Hedgerows which contain mature trees. Structurally similar to a linear strip of broadleaved woodland; average width 15 metres 
The contribution of each hedge type as a habitat area was calculated using the average width values obtained from field measurements. Finally a GIS geoprocessing clip was used to ensure seamless landcover with no overlap between the different variable layers for each study tetrad.

\section{Landscape configuration variables}

Landscape configuration metrics were created using information on the number, amount and spatial pattern of the landcover variables (Table 1). Discrete woodland patches were at least 15 metres apart or where woodland was dissected by a main transport route as this poses a barrier to movement for many flightless carabids (Koivula, 2005). Functionally, 15 metres is considered to be above the 'interaction distance' and mean rate of daily movement for common woodland carabids (Digweed et al., 1995; Brouwers and Newton, 2009a). Woodland habitat extending beyond a tetrad border was taken into account when calculating the sample woodland patch metrics. Isolated woodlands were defined as having no other woodland or any category of hedgerow within $25 \mathrm{~m}$ of their edge, while the length of hedgerows was used as a proxy for structural connectivity within tetrads. All proximity calculations were taken from the centre of the sample woodland using Euclidean distance to the nearest neighbour feature.

Table 1: Summary of the landscape composition, landscape configuration and additional constraining variables calculated for each $2 \times 2 \mathrm{~km}$ study tetrad.

\begin{tabular}{|c|c|c|c|c|}
\hline Composition model & Variables & Mean & Min & Max \\
\hline \multirow[t]{2}{*}{ Woodland habitat } & Area (ha) of broadleaved/mixed woodland & 95 ha & 29 ha & 200 ha \\
\hline & Area (ha) of coniferous plantation & 14 ha & 0 ha & 135 ha \\
\hline \multirow[t]{3}{*}{ Semi-natural habitat } & Area (ha) of scrub/rough grassland & 1 ha & 0 ha & 4 ha \\
\hline & Area (ha) of scattered trees & 4 ha & 0 ha & 19 ha \\
\hline & Area (ha) of inland water & 1 ha & 0 ha & 7 ha \\
\hline \multirow[t]{3}{*}{ Linear habitat $^{a}$} & Area (ha) of low, managed hedge $(\mathrm{H} 1)$ & 2 ha & 0.2 ha & 5 ha \\
\hline & Area (ha) of shrubby hedge $(\mathrm{H} 2)$ & 3 ha & 0.6 ha & 8 ha \\
\hline & Area (ha) of mature hedge with trees $(\mathrm{H} 3)$ & 8 ha & 1 ha & 25 ha \\
\hline \multirow[t]{2}{*}{ Agricultural habitat } & Area (ha) of arable land & 131 ha & 21 ha & 220 ha \\
\hline & Area (ha) of improved grassland & 76 ha & 5 ha & 156 ha \\
\hline \multirow[t]{2}{*}{ Man-made habitat } & Area (ha) of urban land-use & 18 ha & 0.4 ha & 71 ha \\
\hline & Length $(\mathrm{m})$ of main transport routes & $2.2 \mathrm{~km}$ & $0 \mathrm{~km}$ & $4.7 \mathrm{~km}$ \\
\hline Configuration model & Variables & Mean & Min & Max \\
\hline Woodland & Number of woodland patches & 19 & 6 & 45 \\
\hline \multirow[t]{2}{*}{ configuration } & Length $(m)$ of woodland edge & $8.7 \mathrm{~km}$ & $19.9 \mathrm{~km}$ & $35.6 \mathrm{~km}$ \\
\hline & Number of isolated woodland patches & 4 & 0 & 14 \\
\hline
\end{tabular}




\begin{tabular}{lllll} 
in the matrix ${ }^{b}$ & Perimeter: Area ratio of sample wood patch & 1.6 & 0.5 & 3.3 \\
& Distance $(\mathrm{m})$ to nearest woodland patch & $279 \mathrm{~m}$ & $37 \mathrm{~m}$ & $624 \mathrm{~m}$ \\
Hedgerow & Length $(\mathrm{km})$ of all hedgerow types & $16 \mathrm{~km}$ & $5 \mathrm{~km}$ & $46 \mathrm{~km}$ \\
connectivity & Length $(\mathrm{km})$ of low, managed hedge $(\mathrm{H} 1)$ & $7 \mathrm{~km}$ & $0.8 \mathrm{~km}$ & $21 \mathrm{~km}$ \\
& Length $(\mathrm{km})$ of shrubby hedge $(\mathrm{H} 2)$ & $4 \mathrm{~km}$ & $0.7 \mathrm{~km}$ & $11 \mathrm{~km}$ \\
& Length $(\mathrm{km})$ of mature hedge with trees $(\mathrm{H} 3)$ & $6 \mathrm{~km}$ & $0.8 \mathrm{~km}$ & $17 \mathrm{~km}$ \\
Proximity from centre & Distance $(\mathrm{m})$ to nearest transport route & $652 \mathrm{~m}$ & $121 \mathrm{~m}$ & $>2 \mathrm{~km}$ \\
of sample wood patch & Distance $(\mathrm{m})$ to nearest patch of scrub & $431 \mathrm{~m}$ & $56 \mathrm{~m}$ & $>2 \mathrm{~km}$ \\
to matrix features & Distance $(\mathrm{m})$ to nearest water feature & $513 \mathrm{~m}$ & $48 \mathrm{~m}$ & $>2 \mathrm{~km}$ \\
\hline Constraining variables & & & & \\
\hline Sampling Date & Date of first carabid collection after 7 days (fortnight mid-point) \\
Spatial Location & British National Grid coordinate (XY) at tetrad mid-point & & \\
\hline
\end{tabular}

a Full hedgerow category descriptions outlined in 'landscape composition variables' section.

${ }^{b}$ Woodland configuration includes both broadleaved and mixed habitats due to their contiguous nature. Variables representing woodland habitats, semi-natural habitats and urban areas were derived from OS MasterMap (Ordnance Survey, 2010); agricultural habitats were obtained from UK Land Cover Map 2000 (Fuller et al., 2002); linear habitats were digitised from aerial imagery (Terra Metrics, 2009); transport routes were from OS Strategi data (Ordnance Survey, 2012).

\section{Additional constraining variables}

Constraining variables can hamper the detection of true landscape effects on carabid communities (Table 1). During analyses, the effects of Sampling Date (given that carabids were sampled in tetrads over different time periods), and spatial autocorrelation were accounted for (Heikkinen et al., 2004; Oliver et al., 2010).

\section{Statistical analyses}

Direct gradient analyses, variation partitioning and response trait analyses were performed in Canoco v.5 (ter Braak and Šmilauer, 2012) to ascertain the importance of landscape heterogeneity on woodland carabid communities with respect to the four questions posed. For all analyses, the full matrix of carabids recorded were log $(x+1)$ transformed to reduce the impact of abundant species on the results (Vanbergen et al., 2005; ter Braak and Šmilauer, 2012). Prior to analyses a log $(x+1)$ transformation was also applied to a selection of the landscape composition variables (those measured in ha) to maximise the linearity of their relation and ensure that the ecological importance of all the landcover types was considered (Cleveland, 1993; ter Braak and Šmilauer, 2012). 
The effect of i) landscape composition and ii) landscape configuration variables (Table 1) on woodland carabid communities were analysed separately in different models using partial canonical correspondence analyses ( $\mathrm{PCCA}$ ) followed by partial interactive forward selection (pIFS). Partial methods were used to take account of, and remove any explanatory effect of Sampling Date on the carabid community variation. For each model, a constrained ordination ( $p C C A$ ) containing all the landscape composition, or all the landscape configuration variables (Table 1) was run first to check for significance of the joint effects (ter Braak and Šmilauer, 2012). A global permutation test is considered significant where $p$-value $<0.05$ using 9999 Monte-Carlo permutations. Due to the relatively high number of explanatory variables, a conservative $p$-value $<0.01$ was used in order to firmly reject the null hypothesis that 'species communities are randomly attributed to each study tetrad irrespective of the landscape heterogeneity'. Multicollinearity between explanatory variables can occur in spatially defined landscapes where landcover composition sums to 1 (Heikkinen et al., 2004). In both pCCA models the correlation matrix and variance inflation factors (VIF) were consulted during the global permutation test to check for collinearity (ter Braak and Šmilauer, 2012). Correlation coefficients among the final explanatory variables were all less than 0.6 (cf. Aviron et al., 2005; Radford and Bennett, 2007).

Following significant global permutation ( $\mathrm{pCCA}$ ) results for each model, partial interactive forward selection (pIFS) was used to identify a subset of landscape composition and landscape configuration variables which best summarized the carabid community variation. In both models, significant explanatory variables were determined by $p$-value $<0.05$ and confirmed using $p$ values set by the false discovery rate method adjusted for Type 1 error (ter Braak and Šmilauer, 2012). Bi-plots were used to provide a graphical representation of the results. Landscape arrows point in the direction of the steepest increase in a variables value; a small angle between arrows indicates a positive correlation in landscape values while opposing arrows represent a landscape gradient e.g., from grassland to woodland landcover. Within the Canoco v. 5 software, the approximate optima of individual carabid species in respect to values for each of the landscape variables was inferred by projecting the species symbols onto the landscape arrows shown on each bi-plot. This inference of niche optima is underpinned by some assumptions, including that species have unimodal distributions along the landscape variable of interest (see Legendre and Legendre, 1998, p.600), but provides a useful indication of species response in respect to different landscape values (ter Braak and Šmilauer, 2012).

Variation partitioning was performed to ascertain the unique contributions of the landscape composition variables and the landscape configuration variables (identified by pIFS), plus their 
shared effect in explaining carabid community variation. Specialized variation partitioning with principal coordinates of neighbour matrices (PCNM) was used to test for spatial autocorrelation. Tetrads in close proximity to each other can possess more similar landscape or biotic conditions than those from a random set of observations (Heikkinen et al., 2004). The PCNM method separates the variation explained by spatial location from that explained by landscape variables by representing space as geographic ( $\mathrm{X} Y$ ) Euclidean distances among cases (Borcard and Legendre, 2002).

Finally, response trait analyses were used test the null hypothesis that 'carabid communities within study tetrads that are significantly associated with landscape variables, cannot be explained by species life-history or ecological traits'. The sequential two stage test confirmed the results of partial interactive forward selection and then summarized any relationships which existed between the range of species traits possessed by the whole carabid community and the landscape variables.

\section{Results}

\section{Carabid dynamics}

A total of 4677 individuals from 76 species were identified during the sampling period. Woodland and widespread generalist species were the most frequently recorded carabids. The five most commonly occurring species were Pterostichus madidus (1809, 39\% of the total), Abax parallelepipedus (1354, $29 \%$ of the total), Pterostichus melanarius (303, $6 \%$ of the total), Nebria brevicollis (162, 3\% of the total) and Calathus rotundicollis (155, $3 \%$ of the total) representing $78 \%$ of the total carabid composition. Other species recorded frequently but in lower abundances included those inhabiting grasslands, open habitats, agricultural land and heathland.

\section{Effect of spatial location}

Principal coordinates of neighbour matrices (PCNM) found no spatially conditioned variation in the landscape composition $(p=0.260)$ or landscape configuration variables $(p=0.530)$ which could explain the community composition of carabid species. 


\section{Landscape composition and carabid communities}

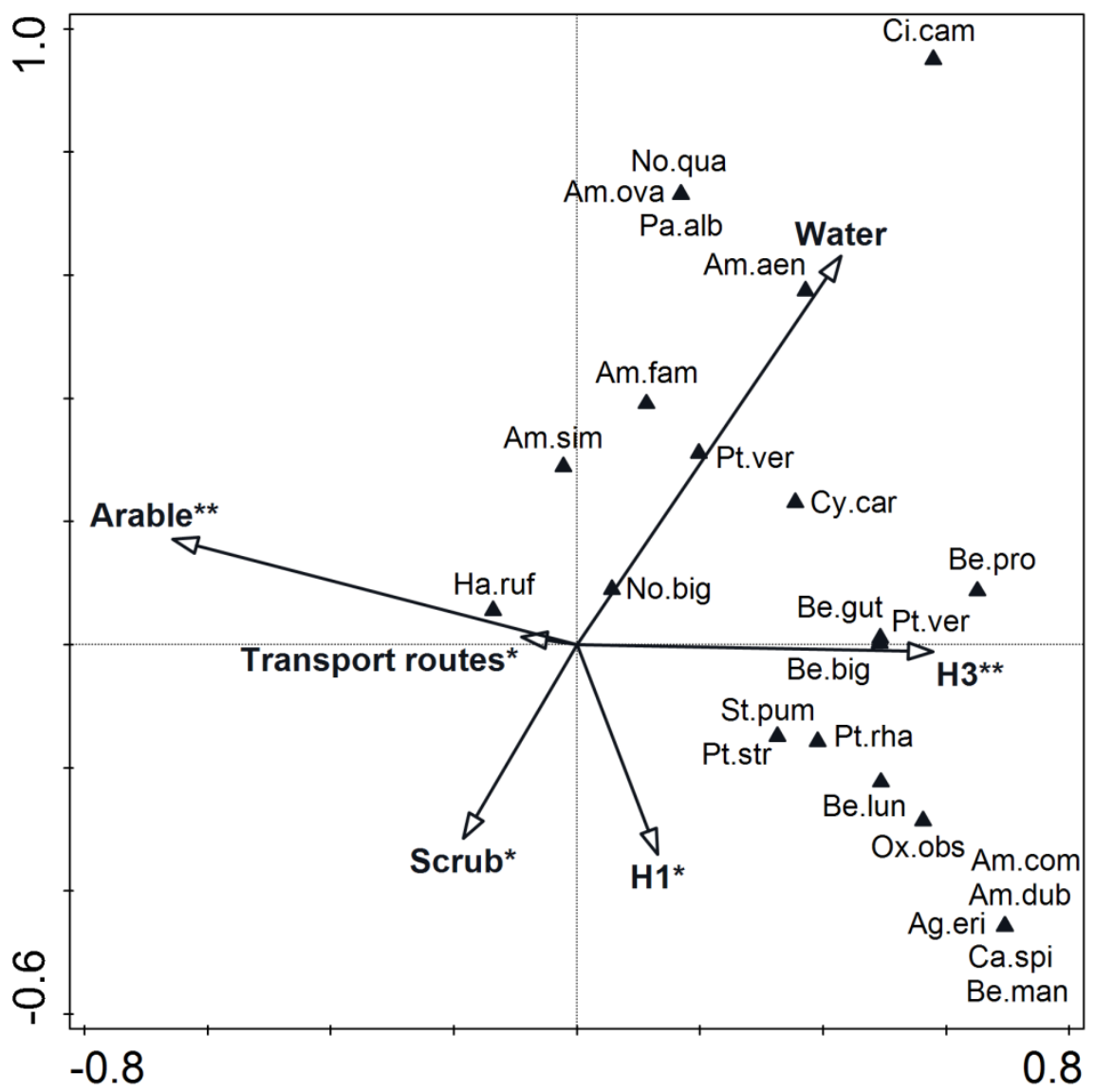

Figure 2: Partial canonical correspondence analysis (pCCA) bi-plot illustrating key landscape composition variables explaining differences in carabid assemblages as identified by partial interactive forward selection (pIFS). Significance of variables determined by Monte-Carlo global permutation tests; no symbol $\mathrm{p}<0.1, * \mathrm{p}<0.05,{ }^{* *} \mathrm{p}<0.01$. Bi-plot displays 25 species with the largest fit in the ordination space. Refer to Table S1 in Appendix 1 for full species names and Methods section for hedgerow descriptions.

Partial canonical correspondence analysis (pCCA) testing joint effects of all landscape composition variables explained $44.8 \%$ of the total variation in woodland carabid assemblages (F $=1.5, \mathrm{p}<0.001)$. Partial interactive forward selection identified six explanatory variables explaining $26.7 \%$ of the variation (Figure 2). Variation in woodland carabid communities could not be attributed to one dominant landscape composition variable. Rather, assemblages were most strongly influenced by increased amounts of mature hedgerows containing trees $(H 3)(p=$ 0.007), low-lying intensively managed hedgerows $(H 1)(p=0.019)$, and decreased amounts of arable land $(p=0.009$ ) in the landscape (Figure 2). Combined, these three variables contributed equally to approximately $16 \%$ of the total explained variation. Other explanatory variables included the amount of inland water $(p=0.079)$, scrub/rough grassland $(p=0.034)$ and length of transport routes ( $p=0.025$ ) (Figure 2 ). Variations in landscape composition impacted most 
strongly on species less frequently encountered in the study such as Amara similata (11 individuals from 4 tetrads) and Bembidion lunulatum (19 individuals, 3 tetrads). Other more habitually occurring species such as Harpalus rufipes (67 individuals, 12 tetrads), Pterostichus strenuus (63 individuals, 16 tetrads) and Notiophilus biguttatus (48 individuals, 18 tetrads) also exhibited a response, indicating the result was not solely influenced by the presence of infrequently trapped species (Figure 2).

The cluster of Bembidion, Amara, and Agonum species ordinated at the apex of the H3 arrow on the bi-plot (Figure 2) indicates their prevalence in tetrads that contained more than $6 \mathrm{~km}$ of mature hedge. The opposing projection of the arable arrow suggests the same species were negatively impacted when arable land exceeded 110 ha or $27 \%$ of the matrix cover. The absence of any carabids at this end of the bi-plot implies extensive arable cover was unfavorable for many of the species studied. Species ordinated between the $\mathrm{H} 3$ and $\mathrm{H} 1$ arrows showed high scores in respect to these two variables indicating an association with tetrads that contained substantial hedgerow networks (Figure 2). Notiophilus quadripunctatus, Amara ovata, Paranchus albipes and Cicindela campestris were strongly associated with increased amounts of inland water, however with the exception of $P$. albipes none of these species are hydrophilic (Luff, 2007).

\section{Landscape configuration and carabid communities}

All landscape configuration variables explained $38.8 \%$ of the total variation in carabid assemblages and the global permutation test was significant ( $p C C A, F=1.4, p=0.002$ ). Interactive forward selection identified six explanatory variables, accounting for $25.9 \%$ of the total carabid variation (Figure 3). Mature hedges $(H 3)(p=0.008)$ and low-lying hedges $(H 1)(p=$ 0.053 ) when included as linear connecting elements explained $11 \%$ of the total variation and were associated with the same cluster of Bembidion, Amara and Agonum species observed in the landscape composition model (Figures 2 and 3). These species were also associated with woodland edge habitat $(p=0.029)$ and an increased number of wood patches $(p=0.010)$. Frequently trapped woodland species $A$. parallelepipedus and $P$. madidus optimally occurred where woodland was less fragmented. However, of the 25 species on the bi-plot they were the least negatively affected by the presence of isolated wood patches $(p=0.011)$ and close proximity of transport routes $(p=0.015)$, despite being brachypterous (Luff, 2007). 


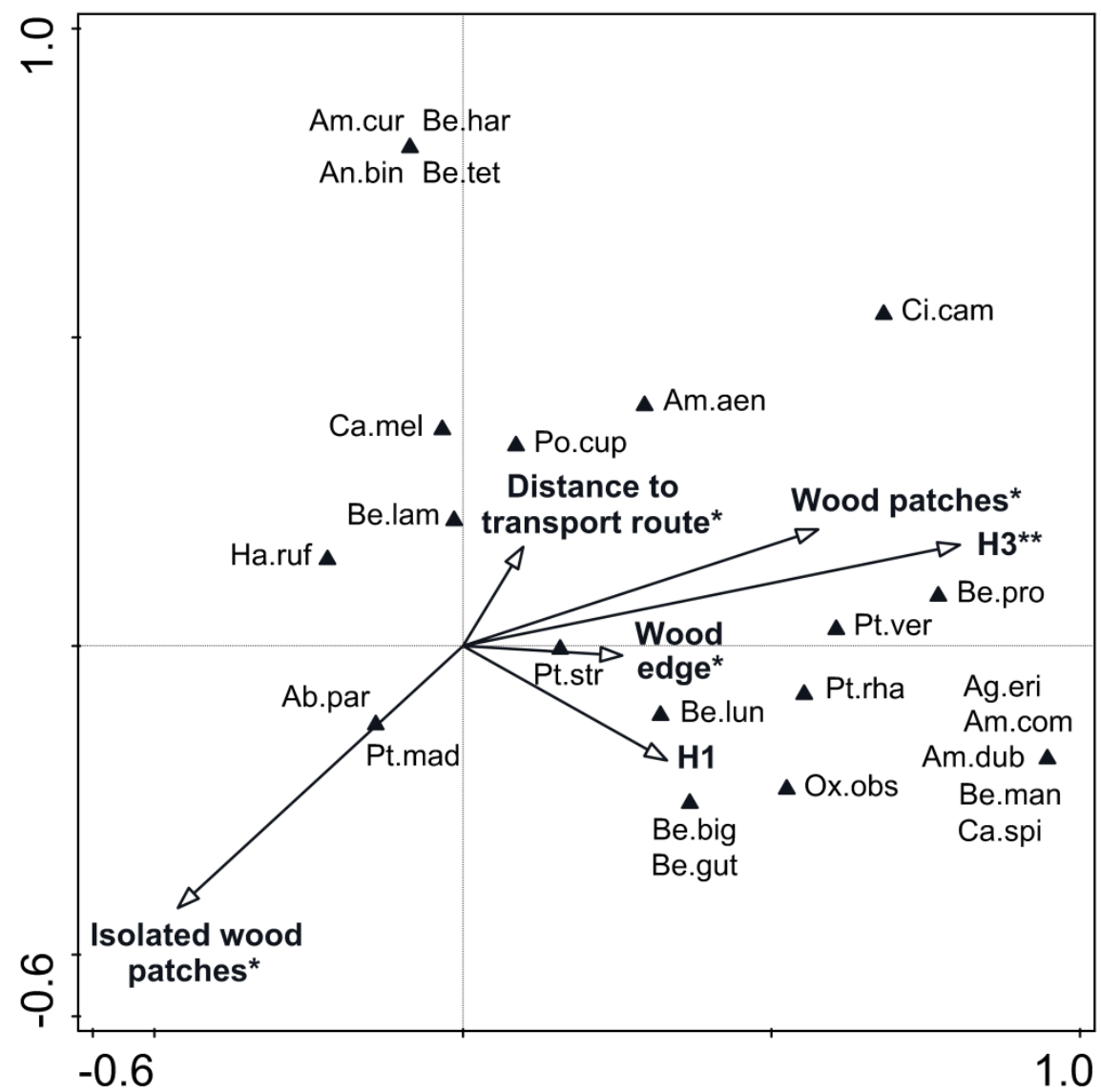

Figure 3: Partial canonical correspondence analysis (pCCA) bi-plot illustrating key landscape configuration variables explaining differences in carabid assemblages as identified by partial interactive forward selection (pIFS). Significance of variables determined by Monte-Carlo global permutation tests; no symbol $\mathrm{p}<0.1, * \mathrm{p}<0.05, * * \mathrm{p}<0.01$. Bi-plot displays 25 species with the largest fit in the ordination space. Refer to Table S1 in Appendix 1 for full species names and Methods section for hedgerow descriptions.

\section{Variation partitioning}

Mature hedgerows containing trees $(\mathrm{H} 3)$ and low, managed hedgerows $(\mathrm{H} 1)$ were significant variables in both pIFS models. Partitioning their effects separately provided an indication of their relative importance as habitat cover and linear connections (Figure 4).

The total amount of variation captured by both landscape composition and configuration variables was $38.0 \%$ when representing hedgerows as habitat cover (Figure 4a). Landscape composition explained a substantially greater proportion of variation $(22.9 \%, p=0.005)$ than landscape configuration variables which, without hedgerows, only explained $11.3 \%$ and were non-significant $(p=0.138)$. Expressing hedgerows as linear elements increased the total variation explained to $39.2 \%$ : configuration variables now explained the largest proportion (21.7\%) and 
significance had increased $(p=0.002)$. Without hedgerows, landscape composition variables still contributed a significant 13.3\% explanatory power (Figure 4b). The joint effect was small for both models indicating a low degree of explanatory overlap between landscape composition and landscape configuration variables (Figure 4).

a) Hedgerows expressed as habitat cover variables

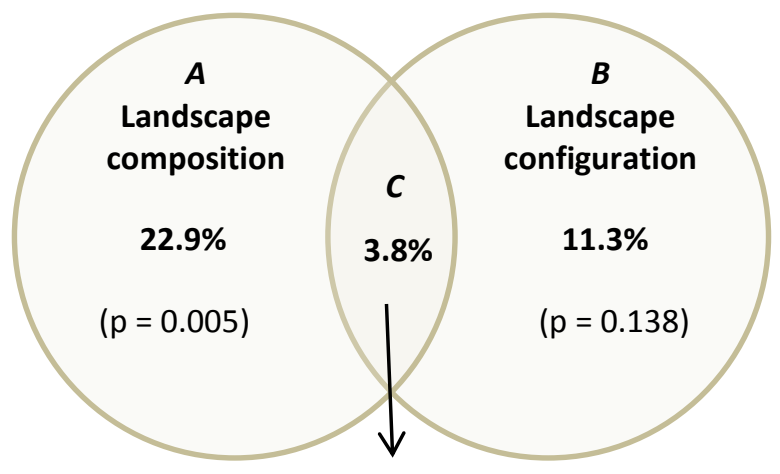

$(p<0.001)$ b) Hedgerows expressed as linear structural elements

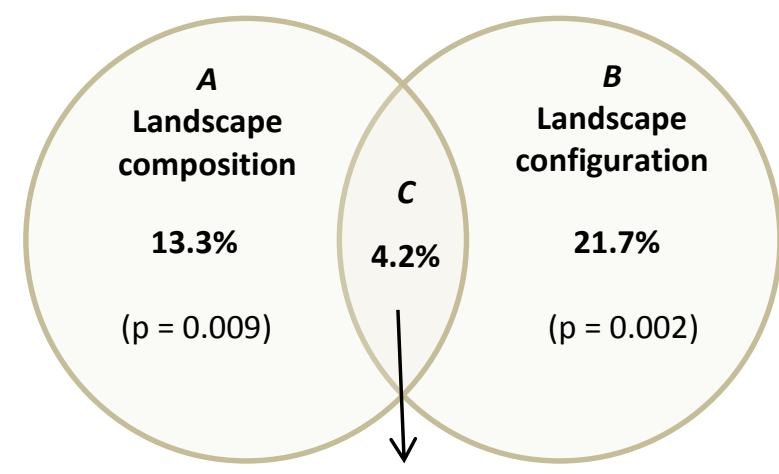

$(p<0.001)$

Figure 4: Results of variation partitioning for the total carabid community composition in terms of fractions of variation explained by landscape composition variables and landscape configuration variables. a) Hedgerow types $\mathrm{H} 1$ and $\mathrm{H} 3$ represented as habitat cover variables (included in group $A$ and omitted from group $B$ ). b) Hedgerow types $\mathrm{H} 1$ and $\mathrm{H} 3$ represented as linear structural elements (omitted from group $A$ and included in group $B$ ).

In both diagrams $A$ and $B$ are unique effects of landscape composition and landscape configuration variables respectively, and $C$ indicates the joint effect.

\section{Life-history traits and ecological groups}

Body size was the only life-history trait to be significant in both models $(6.7 \%, p=0.009$ and $7.4 \%, p=0.003$ ) (Table 2). The distribution of small-bodied carabids $(<4.5 \mathrm{~mm}$ ) within woodlands was positively influenced by an increase in the total length of transport routes and woodland edge habitat while larger carabids (>10 $\mathrm{mm}$ ) reacted opposingly to both. Small-bodied species were also associated with large amounts of managed hedgerow cover $(\mathrm{H} 1)$ in the tetrads. Variation in carabid response to the composition and configuration of the landscape could not be explained by flight capability (Table 2). In the landscape composition model, there was statistical evidence that breeding season was an explanatory trait shaping woodland carabid communities $(8.8 \%, p=0.026)$. Spring breeders were more frequently encountered in woodlands where the matrix contained increased hedgerow cover. A similar near-significant result was observed for the landscape configuration model $(7.6 \%, p=0.066)$ (Table 2$)$. 
Table 2: Results of response trait analyses showing the percentage of carabid community variation (as determined by landscape composition and configuration variables identified from partial interactive forward selection) which can be explained by carabid life-history and ecological traits possessed by the whole community.

\begin{tabular}{llllllll}
\hline Function & Life-history traits & \multicolumn{2}{l}{ Landscape composition } & \multicolumn{2}{l}{ Landscape configuration } \\
& & Explains \% & F & p-value & Explains \% & F & p-value \\
\hline Dispersal & Body size $(\mathrm{mm})$ & $6.7 \%$ & 3.2 & 0.009 & $7.4 \%$ & 3.6 & 0.003 \\
Dispersal & Wing system & $5.8 \%$ & 1.3 & 0.224 & $1.6 \%$ & 0.7 & 0.635 \\
Phenology & Breeding season & $8.8 \%$ & 2.1 & 0.026 & $7.6 \%$ & 1.7 & 0.066 \\
Specialism & Habitat preference & $28.8 \%$ & 2.3 & 0.019 & $9.9 \%$ & 1.4 & 0.140 \\
\cline { 2 - 5 } Specialism & Moisture requirements & $30.8 \%$ & 2.4 & 0.006 & $6.4 \%$ & 1.5 & 0.068 \\
\hline
\end{tabular}

Tetrads with greater amounts of mature hedges containing trees $(\mathrm{H} 3)$ were associated with hydrophilic carabids found near standing or running water such as Agonum ericeti and Bembidion biguttatum (Figure 2). Species preferring open and agricultural habitats with drier soil conditions existed in woodlands surrounded by large amounts of arable land. Heathland species were identified from tetrads containing numerous woodland patches and increased amounts of inland water. Habitat generalists were suited to patchy woodland configurations where tetrads were most likely to represent a heterogeneous mix of landcover types. Woodland species dominated in damp, woodland habitats and were more positively associated with $\mathrm{H} 3$ as opposed to managed hedgerows $\mathrm{H} 1$. Overall, the effects of landscape composition on carabids were strongly related to species habitat and soil moisture preferences $(28.8 \%, p=0.019$ and $30.8 \%, p=0.006$ respectively) (Table 2 ).

\section{Discussion}

Landscape studies conducted at an intermediate spatial scale, c. $500 \times 500 \mathrm{~m}$ to $2 \times 2 \mathrm{~km}$ (Heikkinen et al., 2004) are increasingly popular because they incorporate multiple landscape elements and are directly relevant to local scale management practices (Haslem and Bennett, 2008). In this study, $2 \times 2 \mathrm{~km}$ provided the opportunity to site each tetrad within a comparable landscape type and avoid features uncharacteristic of lowland agricultural-woodland environments. This is inherently more difficult when working at larger-spatial scales or adopting a grid-based approach (Heikkinen et al., 2004; Hendrickx et al., 2007). 
The forward selection results from the landscape composition and landscape configuration analyses are concordant, with carabid-landscape relationships matching well between the two models. In both cases, the joint effects of explanatory variables explained most of the variation in woodland carabid communities, with relatively low amounts attributable to individual landscape features. This supports the idea that landscapes function as entire ecological units rather than as separate components, and wildlife populations respond not only to the type and amount of habitats, but also the interactions and configuration of the different elements throughout the landscape (Rodewald, 2003; Devictor and Jiguet, 2007; Haslem and Bennett, 2008). The greater amount of total explained variation and small proportion of explanatory overlap between the landscape composition and landscape configuration models during variation partitioning further indicates that a more detailed understanding of how species respond can be achieved when considering both components simultaneously (Barbaro et al., 2007).

\section{The importance of semi-natural habitats and linear features within the matrix}

Semi-natural habitats and linear features were both identified as key variables shaping woodland carabid communities. Despite contributing to a minute proportion of the total landcover in study tetrads, the importance of scrubland/rough grassland and water bodies confirms published evidence that heterogeneity provided by such habitats is vital for maintaining diverse populations in agriculturally modified environments (Schweiger et al., 2005; Vanbergen et al., 2005; Hendrickx et al., 2007; Billeter et al., 2008; Oliver et al., 2010). Mature hedgerows containing trees and low, managed hedgerows were also key variables in both models. Hedgerows are an integral part of the landscape in Britain and other European countries (Hinsley and Bellamy, 2000; Billeter et al., 2008; Duflot et al., 2014) but they are rarely incorporated in matrix-wide studies at the level of detail provided here. The ordination and life-history trait results presented here, supplement other local scale studies. Notably, hedges can provide overwintering habitat for many field-based spring breeding carabids such as Amara spp. They may also replicate local site conditions similar to those found at woodland edges with similar carabid assemblages existing in both habitats (Thomas et al., 2001; Taboada et al., 2004). Mature hedges also frequently line river margins and can provide ditches or damp conditions which are suitable for the survival and dispersal of hydrophilic carabids in agricultural environments (Luff, 2007). Structurally, mature hedges are also known to facilitate the movement and dispersal of larger-bodied, woodland carabids such as Pterostichus spp. (Petit and Burel, 1998; Aviron et al., 2005; Jopp and Reuter, 2005). The presence of $P$. madidus and $A$. parallelepipedus in tetrads containing isolated wood patches is unlikely to be because large species cope better with 
isolation than smaller species (see Schweiger et al., 2005), but because they have been physically unable to disperse (Petit and Burel, 1998; Jopp and Reuter, 2005). Essentially, they are remnant populations from a time when the woodland was part of a larger network (Lindborg and Eriksson, 2004). The most significant result in this study is the clear evidence that hedgerows are imperative structural landscape features for carabids. They explained a substantial proportion of the total variation of all the configuration variables and their elimination from the model during variation partitioning rendered the remaining variables of no significance. Therefore, carabid community response to woodland isolation, increased patchiness and edge habitat could only be identified when incorporating the interactions of hedgerows at the $2 \times 2 \mathrm{~km}$ scale. By extrapolating the patterns presented in both models, the overall trend indicates that hedgerows provide useable habitat within the more inhospitable arable habitat unfavoured by many species and significant functional connectivity through the matrix, particularly where woodland exists in patchy configurations.

\section{Life-history traits and ecological groups}

Habitat preference and moisture requirements were the key ecological traits which determined how species responded to landscape composition. Judas et al., (2002) suggested that for some carabid species, microclimatic habitat associations scale-up to distributions within a landscape. As the majority of carabids collected were typical of woodland habitats the negative influence of widespread arable land is not surprising as species will frequently respond most strongly to the extent of preferred or avoided elements in the landscape (Heikkinen et al., 2004; Aviron et al., 2005). Nonetheless, woodland communities did not notably respond to increased woodland cover, again indicating that diversity provided by other matrix habitats may be more important for species than the extent of focal habitat in a landscape (Kallimanis et al., 2008; Oliver et al., 2010; Fahrig et al., 2011). At the species and trait level, some carabids with explicit habitat requirements, such as $P$. albipes which inhabits water margins (Luff, 2007), did display strong relationships with tetrads containing equivalent landcover types. However, this trend was also not clear-cut; $N$. quadripunctatus and C. campestris were associated with tetrads containing inland water and numerous woodland patches despite being typical of dry, heathland habitat not present within the tetrads at the time of study. Data obtained from the British Land-Utilisation Survey 1933-1949 (Clark, 2011) confirms that lowland heath was widespread throughout the majority of the tetrads prior to the onset of intensive agriculture. Wet mires, bodies of open water and woodland patches are commonly associated with lowland heath (Gimingham, 1972), 
and indicate that species may persist at least for some decades, if elements of the original habitat which can be utilized by individuals are retained (Eyre and Luff, 2004).

It was hypothesized that smaller species would respond differently in comparison to larger carabids and that this could be related to habitat specialization and flight capability. Smaller species $(<4.5 \mathrm{~mm}$ ) were positively influenced, and many larger species negatively so by the presence of roads, railways and increased managed hedgerow cover within tetrads. Small carabids generally display higher rates of species turnover and are capable of readily dispersing between habitats making them suited to occupying disturbed or changeable environments such as road verges, woodland edges and managed hedgerows. Larger species, which are often flightless, slow-dispersers, are associated with more ecologically stable, long-lived habitats such as woodland or mature hedgerows (Kotze and O'Hara, 2003; Brouwers and Newton, 2009a; Korhonen et al., 2010). Flight capability however provided no explanatory power suggesting that it is not consistently correlated with body size and dispersal power. Rather, carabid response can be better attributed to specific species habitat specialization which in some cases is correlated with wing-presence or absence (Kotze and O'Hara, 2003). For example, transport routes negatively affected large, flightless woodland specialists such as Carabus species (Luff, 2007). Conversely, woodland generalists' A. parallelepipedus and $P$. madidus were able to utilize the road and railway verge habitat and respond favourably despite being brachypterous and of comparable size (Brouwers and Newton, 2009a).

\section{Conservation and policy implications}

Carabid community response at a landscape scale is the result of complex interactions relevant to both the type and configuration of different habitats present but also individual species ecological requirements and life-history traits. Studying a diverse group such as carabids demonstrates that features considered unsuitable for one species may be readily utilized by others even when they are closely related. With demands for land-use intensifying plus additional factors such as climate change, there is a need to design and manage landscapes to increase heterogeneity and buffer populations by focusing on semi-natural and linear habitats (Schweiger et al., 2005; Vanbergen et al., 2005; Hendrickx et al., 2007; Haslem and Bennett, 2008; Oliver et al., 2010; Fahrig et al., 2011). Although this is recognized in European policy, the biodiversity benefits of agri-environment schemes remain questionable (Davey et al., 2010), arguably because the choice of options do not consider the type, configuration and interactions of the wider surroundings (Aviron et al., 2005; Fahrig et al., 2011). It has been demonstrated that defining different types of semi-natural and linear habitats improves understanding of specific 
species-landscape interactions than can be achieved by grouping them together under one umbrella term (Haslem and Bennett, 2008). Information of this type can be applied at the individual landowner scale to inform conservation and land management decisions. Hedgerows or comparable linear habitat should be a priority option where woodlands exist as smaller, isolated patches in the surrounding landscape. Semi-natural habitats and linear features should also be actively preserved and matrix heterogeneity encouraged wherever possible (Aviron et al., 2005; Hendrickx et al., 2007; Haslem and Bennett, 2008). Mature hedgerows should be retained along water margins and where semi-natural habitat is threatened or lost to other land-use demands, effort should be focused on retaining or replacing features characteristic of the original environment as this may help encourage species to persist (Bakker and Berendse, 2001; Piessens and Hermy, 2006). In conclusion, agri-environment options should be targeted at the individual landowner level using ecological knowledge obtained about the current and, where appropriate, historic land-use to maximise biodiversity benefits.

\section{Acknowledgments}

We are grateful to the Game and Wildlife Conservation Trust for the funding provided, to landowners who granted us permission to access their land and to Chris Foster for help with fieldwork. Finally, thanks to Jonathan Bradley for his comments and corrections on the first draft of this manuscript.

\section{References}

Aviron S, Burel F, Baudry J et al (2005) Carabid assemblages in agricultural landscapes: impacts of habitat features, landscape context at different spatial scales and farming intensity. Agric Ecosyst Environ 108:205-217

Bakker JP, Berendse F (2001) Constraints in the restoration of ecological diversity in grassland and heathland communities. Trends Ecol Evol 14:63-68

Barbaro L, Rossi J-P, Vetillard F et al (2007) The spatial distribution of birds and carabid beetles in pine plantation forests: the role of landscape composition and structure. J Biogeogr 34:652-664

Barbaro L, van Halder I (2009) Linking bird, carabid beetle and butterfly life history traits to habitat fragmentation in mosaic landscapes. Ecography 32:321-333

Bellamy P, Hinsley SA, Newton I (1996) Factors influencing bird species numbers in small woods in south-east England. J Appl Ecol 33:249-262

Bennett AF, Radford JQ, Haslem A (2006) Properties of land mosaics: implications for nature conservation in agricultural environments. Biol Conserv 133:250-264 
Billeter R, Liira J, Bailey D et al (2008) Indicators for biodiversity in agricultural landscapes: a panEuropean study. J Appl Ecol 45:141-150

Borcard D, Legendre P (2002) All-scale spatial analysis of ecological data by means of principal coordinates of neighbour matrices. Ecol Model 153:51-68

Brouwers N, Newton AC (2009) Movement rates of woodland invertebrates: a systematic review of empirical evidence. Insect Conserv Divers 2:10-22

Clark AN (no date) Data from: The land utilisation survey of Britain, 1933-1949 (unpublished). Coverage: Great Britain. Environment Agency and obtained under Special Non-Commercial licence. Available from http://data.gov.uk/dataset/digital-land-utilisation-survey-1933-1949afa213

Cleveland WS (1993) Visualizing Data. Hobart Press, New Jersey

Cushman SA, McGarigal K (2003) Landscape-level patterns of avian diversity in the Oregon Coast Range. Ecol Monogr 73:259-281

Daily GC, Ehrlich P, Sánchez-Azofeifa A (2001) Countryside biogeography: use of humandominated habitats by the avifauna of southern Costa Rica. Ecol Appl 11:1-13

Davey CM, Vickery JA, Boatman ND et al (2010) Assessing the impact of Entry Level Stewardship on lowland farmland birds in England. Ibis 152:459-474

Devictor V, Jiguet F (2007) Community richness and stability in agricultural landscapes: The importance of surrounding habitats. Agric Ecosyst Environ 120:179-184

Digweed SC, Currie CR, Carcamo HA et al (1995) Digging out the "digging-in-effect" of pitfall traps: influences of depletion and disturbance on catches of ground beetles (Coleoptera: Carabidae). Pedobiologia 39:561-576

Dray S, Choler P, Dole S et al (2014) Combining the fourth-corner and the RLQ methods for assessing trait responses to environmental variation. Ecology 95:14-21

Duflot R, Georges R, Ernoult A et al (2014) Landscape heterogeneity as an ecological filter of species traits. Acta Oecol 56:19-26

Eyre MD, Luff ML (2004) Ground beetle species (Coleoptera, Carabidae) associations with land cover variables in northern England and southern Scotland. Ecography 27:417-426

Fahrig L (2003) Effects of habitat fragmentation on biodiversity. Annu Rev Ecol Evol Syst 34:487515

Fahrig L, Baudry J, Brotons L et al (2011) Functional landscape heterogeneity and animal biodiversity in agricultural landscapes. Ecol Lett 14:101-112

Firbank LG, Petit S, Smart S et al (2007) Assessing the impacts of agricultural intensification on biodiversity; a British perspective. Phil Trans R Soc B 363:777-787 
Forsythe TG (2000) Ground Beetles, Naturalists' Handbook 8. Richmond Publishing, Newbury, UK Fuller RM, Smith GM, Sanderson JM et al (2002) Data from: Land Cover Map 2000. Centre for Ecology and Hydrology and Natural Environment Research Council. Coverage: Great Britain. Available from http://www.ceh.ac.uk/landcovermap2000.html

Gardiner T (2007) Orthoptera of crossfield and headland footpaths in arable farmland. J Orthoptera Res 16:127-133

Gibb H, Hjalten J, Ball J et al (2006) Wing loading and habitat selection in forest beetles: Are redlisted species poorer dispersers or more habitat-specific than common congenerics? Biol Conserv 132:150-160

Gimingham CH (1972) Ecology of Heathlands. Chapman Hall, London

Green RE, Osborne PE, Sears EJ (1994) The distribution of passerine birds during the breeding season in relation to characteristics of the hedgerow and adjacent farmland. J Appl Ecol 31:677692

Haslem A, Bennett AF (2008) Birds in agricultural mosaics: The influence of landscape pattern and countryside heterogeneity. Ecol Appl 18:185-196

Heikkinen RK, Luoto M, Virkkala R et al (2004) Effects of habitat cover, landscape structure and spatial variables on the abundance of birds in an agricultural forest mosaic. J Appl Ecol 41:824835

Hendrickx F, Maelfait J, Van Wingerden W et al (2007) How landscape structure, land-use intensity and habitat diversity affect components of total arthropod diversity in agricultural landscapes. J Appl Ecol 44:340-351

Hinsley SA, Bellamy PE (2000) The influence of hedge structure, management and landscape context on the value of hedgerows to birds: a review. J Environ Manag 80:33-49

Hooftman DAP, Bullock JM (2012) Mapping to inform conservation: A case study of changes in semi-natural habitats and their connectivity over 70 years. Biol Cons 145:30-38

Jopp F, Reuter H (2005) Dispersal of carabid beetles - emergence of distribution patterns. Ecol Model 186:389-405

Judas M, Dornieden K, Strothmann U (2002) Distribution patterns of carabid beetle species at the landscape-level. J Biogeogr 29:491-508

Kallimanis AS, Mazaris AD, Tzanopoulos J et al (2008) How does habitat diversity affect the species-area relationship? Global Ecol Biogeogr 17:535-538

Kang B, Lee J-H, Park J-K (2012) Carabid beetle species as a biological indicator for different habitat types of agricultural landscapes in Korea. J Ecol Field Biol 35:35-39

Koivula M (2005) Effects of forest roads on spatial distribution of boreal carabid species (Coleoptera; Carabidae). Coleopt Bull 59:465-487 
Korhonen JJ, Soininen J, Hillebrand H (2010) A quantitative analysis of temporal turnover in aquatic species assemblages across ecosystems. Ecology 91:508-517

Kotze JD, O'Hara RB (2003) Species decline: but why? Explanations of carabid beetle (Coleoptera, Carabidae) declines in Europe. Oecologia 135:138-148

Larcher F, Baudry J (2013) Landscape grammar: a method to analyse and design hedgerows and networks. Agrofor Syst 87:181-192

Lavorel S, Mcintyre S, Landsberg J et al (1997) Plant functional classifications: from general groups to specific groups based on response to disturbance. Trends Ecol Evol 12:474-478

Lawton H, Brotherton PNM, Brown VK et al (2010) Making Space for Nature: a review of England's wildlife sites and ecological network. Report to Defra. Available from http://archive.defra.gov.uk/environment/biodiversity/documents/201009space-for-nature.pdf (accessed 12 June 2013)

Legendre P, Legendre L (1998) Numerical Ecology. $2^{\text {nd }}$ Edition. Elsevier Science, Amsterdam, Netherlands

Lindborg R, Eriksson O (2004) Historical landscape connectivity affects present plant species diversity. Ecology 85:1840-1845

Luff ML (2007) The Carabidae (ground beetles) of Britain and Ireland. FSC Publications, Shrewsbury, Shropshire

Mason WL (2007) Changes in the management of British forests between 1945 and 2000 and possible future trends. Ibis 149:41-52

Mayfield M, Bonser SP, Morgan J et al (2010) What does species richness tell us about functional trait diversity? Predictions and evidence for responses of species and functional trait diversity to land-use change. Global Ecol Biogeogr 19:423-431

Mayfield M, Daily G (2005) Countryside biogeography of neotropical herbaceous and shrubby plants. Ecol Appl 15:423-439

McGarigal K, Ene E (2012) Fragstats 4.1: A spatial pattern analysis program for categorical maps. Computer software program produced by the authors at the University of Massachusetts, Amherst. Available from http://www.umass.edu/landeco/research/fragstats/fragstats.html

Öckinger E, Smith HG (2006) Landscape composition and habitat area affects butterfly species richness in semi-natural grasslands. Oecologia 149:526-534

Oliver T, Roy DB, Hill JK et al (2010) Heterogeneous landscapes promote population stability. Ecol Lett 13:473-484

Ordnance Survey (2010) MasterMap Download. Edina Digimap. Data obtained under licence. Available from http://digimap.edina.ac.uk/mastermapdownloader/Downloader 
Ordnance Survey (2012) OS Open Source. Coverage: Great Britain. Updated 2011, Ordnance Survey Open Data, GB. Available from http://www.ordnancesurvey.co.uk/oswebsite/products/

Petit S, Burel F (1998) Effects of landscape dynamics on the metapopulation of a ground beetle (Coleoptera, Carabidae) in a hedgerow network. Agric Ecosyst Environ 69:243-252

Piessens K, Hermy M (2006) Does the heathland flora in north-western Belgium show an extinction debt? Biol Conserv 132:382-394

Piqueray J, Bisteau E, Cristofoli S et al (2011) Plant species extinction debt in a temperate biodiversity hotspot: Community, species and functional traits approaches. Biol Conserv 144:1619-1629

Purtauf T, Roschewitz I, Dauber J et al (2005) Landscape context of organic and conventional farms: influences on carabid beetle diversity. Agric Ecosyst Environ 108:165-174

Radford JQ, Bennett AF (2007) The relative importance of landscape properties for woodland birds in agricultural environments. J Appl Ecol 44:737-747

Ribera I, Dec S, Downie I et al (2001) Effect of land disturbance and stress on species traits of ground beetle assemblages. Ecology 84:1112-1129

Rodewald AD (2003) The importance of land uses within the landscape matrix. Wildl Soc Bull 31:586-592

Schweiger O, Maelfait JP, Van Wingerden et al (2005) Quantifying the impact of environmental factors on arthropod communities in agricultural landscapes across organizational levels and spatial scales. J Appl Ecol 42:1129-1139

Šmilauer P, Leps J (2014) Multivariate analysis of ecological data using Canoco 5. Second Edition. Cambridge University Press. United Kingdom

Taboada A, Kotze DJ, Salgado JM (2004) Carabid beetle occurrence at the edges of oak and beech forests in NW Spain. Eur J Entomol 101:555-563

Ter Braak CJF, Šmilauer P (2012) Canoco reference manual and user's guide: software for ordination. Version 5.0. Microcomputer Power, Ithaca, USA

Terra Metrics (2009) Google Maps UK. Available from https://www.google.co.uk/maps/ (accessed 11 June 2011)

Thomas CG, Parkinson L, Griffiths GJK et al (2001) Aggregation and temporal stability of carabid beetle distributions in field and hedgerow habitats. J Appl Ecol 38:100-116

Vanbergen AJ, Woodcock BA, Watt AD et al (2005) Effect of land-use heterogeneity on carabid communities at the landscape scale. Ecography 28:3-16

Ward DF, New TR, Yen AL (2001) Effects of pitfall trap spacing on the abundance, richness and composition of invertebrate catches. J Insect Conserv 5:47-5 


\section{Appendix 1}

Table S1: Record of carabid species life-history traits and individual bi-plot identification code

\begin{tabular}{|c|c|c|c|c|c|c|}
\hline Species name & Bi-plot code & $\begin{array}{l}\text { Average body size } \\
(\mathrm{mm})\end{array}$ & Wing system & Breeding season & Dominant habitat & $\begin{array}{l}\text { Soil moisture } \\
\text { preference }\end{array}$ \\
\hline Asaphidion curtum & Am.cur & 4.1 & Macropterous & Spring & Open & Near water \\
\hline Bembidion aeneum & Be.aen & 4 & Dimorphic & Spring & Woodland & Near water \\
\hline Bembidion biguttatum & Be.big & 4.2 & Macropterous & Spring & Grassland & Near water \\
\hline Bembidion guttula & Be.gut & 3.3 & Macropterous & Spring & All & Near water \\
\hline Bembidion lampros & Be.lam & 3.5 & Dimorphic & Spring & Open & Dry \\
\hline Bembidion lunulatum & Be.lun & 3.7 & Macropterous & Spring & Open & Near water \\
\hline Bembidion mannerheimii & Be.man & 3.1 & Apterous & Spring & Woodland & Damp \\
\hline Bembidion obtusum & Be.obt & 3.1 & Dimorphic & Spring & Open & Dry \\
\hline Bembidion properans & Be.pro & 3.9 & Dimorphic & Spring & Open & Dry \\
\hline Bembidion quadrimaculatum & Be.qua & 3.1 & Macropterous & Spring & Open & Dry \\
\hline Bembidion tetracolum & Be.tet & 5.5 & Apterous & Spring & Agricultural & Near water \\
\hline Ocys harpaloides & Oc.har & 5 & Macropterous & Summer & Woodland & Damp \\
\hline Carabus nemoralis & Ca.nem & 23 & Apterous & Spring & Open & Damp-Dry \\
\hline Carabus problematicus & Ca.pro & 24 & Apterous & Summer & Woodland & Damp \\
\hline
\end{tabular}




\begin{tabular}{|c|c|c|c|c|c|c|}
\hline Carabus violaceus & Ca.vio & 25 & Apterous & Autumn & Woodland & Damp \\
\hline Acupalpus dubius & Ac.dub & 2.7 & Macropterous & Spring & Woodland & Near water \\
\hline Anisodactylus binotatus & An.bin & 11.5 & Macropterous & Spring & Grassland & Damp \\
\hline Bradycellus harpalinus & Br.har & 4.3 & Dimorphic & Autumn & All & Dry \\
\hline Harpalus affinis & Ha.aff & 10.5 & Macropterous & Spring & Agricultural & Dry \\
\hline Harpalus attenuates & Ha.att & 8 & Macropterous & Spring & Open & Dry \\
\hline Harpalus latus & Ha.lat & 9.5 & Macropterous & Summer & Grassland & Dry \\
\hline Harpalus rubripes & Ha.rub & 10.2 & Macropterous & Spring & Grassland & Dry \\
\hline Harpalus rufipes & Ha.ruf & 13.5 & Macropterous & Summer & Agricultural & Dry \\
\hline Ophonus rufibarbis & Op.ruf & 8 & Macropterous & Spring & Open & Damp-Dry \\
\hline Ophonus schaubergerianus & Op.sch & 9 & Macropterous & Spring & Grassland & Dry \\
\hline Leistus fulvibarbis & Le.ful & 7.5 & Macropterous & Summer & Woodland & Damp \\
\hline Leistus rufomarginatus & Le.ruf & 8.7 & Macropterous & Summer & Woodland & Damp \\
\hline Leistus spinnibarbis & Le.spi & 9.3 & Macropterous & Summer & Woodland & Damp \\
\hline Nebria brevicollis & Ne.bre & 12.5 & Apterous & Autumn & All & Damp-Dry \\
\hline Nebria salina & Ne.sal & 12.5 & Apterous & Autumn & Heath & Dry \\
\hline Notiophilus biguttatus & No.big & 5.5 & Dimorphic & Summer & All & Damp-Dry \\
\hline Notiophilus palustris & No.pal & 5 & Dimorphic & Summer & Woodland & Damp \\
\hline Notiophilus quadripunctatus & No.qua & 5.2 & Dimorphic & Spring & Heath & Dry \\
\hline
\end{tabular}




\begin{tabular}{|c|c|c|c|c|c|c|}
\hline Notiophilus rufipes & No.ruf & 6 & Macropterous & Spring & Woodland & Damp \\
\hline Agonum ericeti & Ag.eri & 7.2 & Apterous & Summer & Heath & Near water \\
\hline Agonum fuliginosum & Ag.ful & 6.2 & Apterous & Spring & Grassland & Damp \\
\hline Oxypselaphus obscurus & Ox.obs & 5.8 & Apterous & Spring & Woodland & Damp \\
\hline Paranchus albipes & Pa.alb & 7.6 & Macropterous & Spring & All & Near water \\
\hline Platynus assimilis & Pl.ass & 10.7 & Macropterous & Spring & Woodland & Near water \\
\hline Abax parallelepipedus & Ab.par & 19.5 & Apterous & Summer & Woodland & Damp \\
\hline Poecilus cupreus & Po.cup & 12 & Macropterous & Spring & Grassland & Dry \\
\hline Poecilus versicolor & Po.ver & 11.5 & Apterous & Summer & Grassland & Damp \\
\hline Pterostichus madidus & Pt.mad & 16 & Apterous & Autumn & Woodland & Damp-Dry \\
\hline Pterostichus melanarius & Pt.mel & 15 & Apterous & Autumn & Agricultural & Dry \\
\hline Pterostichus niger & Pt.nig & 18.5 & Apterous & Autumn & Woodland & Damp \\
\hline Pterostichus nigrita/ rhaeticus & Pt.rha & 10.5 & Macropterous & Spring & Grassland & Near water \\
\hline Pterostichus oblongopunctatus & Pt.obl & 10.8 & Macropterous & Spring & Woodland & Dry \\
\hline Pterostichus strenuus & Pt.str & 6.6 & Dimorphic & Spring & All & Damp-Dry \\
\hline Pterostichus vernalis & Pt.ver & 6.8 & Dimorphic & Spring & Grassland & Damp \\
\hline Stomis pumicatus & St.pum & 7.5 & Apterous & Spring & Woodland & Damp \\
\hline Calathus fuscipes & Ca.fus & 12 & Dimorphic & Autumn & Grassland & Dry \\
\hline Calathus melanocephalus & Ca.mel & 7.2 & Apterous & Autumn & Heath & Dry \\
\hline
\end{tabular}




\begin{tabular}{|c|c|c|c|c|c|c|}
\hline Calathus rotundicollis & Ca.rot & 9.5 & Dimorphic & Autumn & Woodland & Damp-Dry \\
\hline Synuchus vivalis & Sy.viv & 7.3 & Macropterous & Autumn & Grassland & Damp-Dry \\
\hline Trechus obtusus & Tr.obt & 3.8 & Apterous & Autumn & Heath & Dry \\
\hline Trechus quadristriatus & Tr.qua & 3.9 & Macropterous & Autumn & Agricultural & Dry \\
\hline Amara aenea & Am.aen & 7.6 & Macropterous & Spring & Grassland & Dry \\
\hline Amara communis & Am.com & 7 & Macropterous & Spring & Grassland & Damp-Dry \\
\hline Amara convexior & Am.con & 7.3 & Macropterous & Spring & Grassland & Dry \\
\hline Amara curta & Am.cur & 6.3 & Macropterous & Spring & Grassland & Dry \\
\hline Amara eurynota & Am.eur & 11 & Macropterous & Autumn & Agricultural & Dry \\
\hline Amara familiaris & Am.fam & 6.4 & Macropterous & Spring & Grassland & Dry \\
\hline Amara lunicollis & Am.lun & 8.2 & Macropterous & Spring & Open & Damp-Dry \\
\hline Amara nitida & Am.nit & 7.8 & Macropterous & Spring & Open & Dry \\
\hline Amara plebeja & Am.ple & 6.9 & Macropterous & Spring & Agricultural & Near water \\
\hline Amara ovata & Am.ova & 8.7 & Macropterous & Spring & Open & Dry \\
\hline Amara similata & Am.sim & 8.7 & Macropterous & Spring & Open & Near water \\
\hline Curtonotus aulicus & Cu.aul & 12.5 & Macropterous & Autumn & Open & Dry \\
\hline Zabrus tenebrioides & Za.ten & 15 & Macropterous & Autumn & Agricultural & Dry \\
\hline Badister bullatus & Ba.bul & 6.5 & Macropterous & Spring & Heath & Dry \\
\hline Calodromius spilotus & Ca.spi & 4.1 & Macropterous & Summer & Woodland & Damp \\
\hline
\end{tabular}




\begin{tabular}{|l|l|l|l|l|l|l|}
\hline Cicindela campestris & Ci.cam & 14.5 & Macropterous & Spring & Heath & Dry \\
\hline Clivina fossor & Cl.fos & 6.4 & Dimorphic & Spring & Agricultural & Damp-Dry \\
\hline Cychrus caraboides & Cy.car & 16.5 & Apterous & Autumn & Woodland & Damp \\
\hline Loricera pilicornis & Lo.pil & 7 & Macropterous & Summer & Grassland & Near water \\
\hline Panagaeus bipustulatus & Pa.bip & 7 & Macropterous & Spring & Grassland & Dry \\
\hline
\end{tabular}

